\title{
Extração e determinação de atividade de peroxidase do nabo, em diferentes estágios de crescimento e analisar a influência dos íon Ca2+ no crescimento in vitro.
}

\author{
Elaine de Lima de Jesus ${ }^{1}$; Heiddy Márquez Alvarez² \\ 1. Bolsista PIBIC/CNPq, Graduando em Farmacia, Universidade Estadual de Feira de Santana, e-mail: \\ elnylima@ hotmail.com \\ 2. Orientador, Departamento Exatas, Universidade Estadual de Feira de Santana, e-mail: marquezheiddy@gmail.com
}

PALAVRAS-CHAVE: atividade peroxidase; nabo; íons bivalentes de Cálcio.

\section{INTRODUÇÃO}

As enzimas são biocatalisadores de origem animal, vegetal ou microbiana, descobertas no século XVIII, em estudos obre digestão de alimentos e os trabalhos de purificação iniciaram após 1920 (FATIBELLO-FILHO et al., 2002).

As enzimas, dentre as principais a peroxidase, apresenta um potencial pela reação com uma gama de compostos orgânicos. A degradação e transformação por catalise acontece por precipitação e/ou ruptura do anel aromático, e toda essa produção e processos demandam custo elevado com baixo rendimento. A redução do custo de produção dessas enzimas pode ser obtida pela utilização de vegetais contendo alta atividade enzimática, e que podem ser aplicados diretamente com a mesma eficiência que a enzima purificada, comparado aos convencionais, já que apresenta limitações devido ao baixo rendimento e o alto custo de produção destes biocatalisadores. (FATIBELLO-FILHO et al., 2002).

O território nacional contém uma vasta variedade de frutas e vegetais, na sua maioria, de baixo custo, sendo uma fonte inesgotável de enzimas com potencial de utilizações in natura ou como estrato bruto, e de simples extração, com vários procedimentos podem envolver diferentes etapas de purificação. Existe interesse na elaboração de pesquisas por estas enzimas pelo motivo de suas aplicações, como por exemplo, a construção de biossensores, industrial, analises bioquímicas, entre outras. (ZERAIK et al. 2008)

O nabo consiste em um tubérculo de melhores adaptabilidade, podendo ser cultivado em uma ampla faixa de variação climática e de solo, com uma possível capacidade de desenvolvimento, quem pode ser corrigida por acréscimo de nutrientes, além de ser uma fonte de produção peroxidase (OLIVEIRA, 2009). Assim, o presente trabalho propõe a análise da atividade peroxidase deste tubérculo, tendo em consideração a influência de diferentes estágios de colheitas e variação de utilização dos íons bivalentes de Cálcio (CA).

\section{MATERIAL E MÉTODOS}

Germinação das sementes:

Para a germinação, foi utilizado o meio Muraschige e Skoog (MS), tendo como composição: nitrato de amônio 82,5 g/L, que compõe a solução A ( $20 \mathrm{~mL}$ da solução para 1L de meio), nitrato de potássio $95 \mathrm{~g} / \mathrm{L}$, que compõe a solução B (20mL da solução para $1 \mathrm{~L}$ de meio), fosfato de potássio $34 \mathrm{~g} / \mathrm{L}$, ácido bórico $1,24 \mathrm{~g} / \mathrm{L}$, molibidato de sódio $0,05 \mathrm{~g} / \mathrm{L}$, cloreto de cobalto $0,005 \mathrm{~g} / \mathrm{L}$, iodeto de potássio $0,166 \mathrm{~g} / \mathrm{L}$ que compõe a solução C ( $5 \mathrm{~mL}$ da solução para $1 \mathrm{~L}$ de meio), cloreto de cálcio 8,8g/L compõe a solução D ( $50 \mathrm{~mL}$ para $1 \mathrm{~L}$ de meio), sulfato de magnésio $74 \mathrm{~g} / \mathrm{L}$, sulfato de mangânes $4,46 \mathrm{~g} / \mathrm{L}$, sulfato de zinco $1,72 \mathrm{~g} / \mathrm{L}$, sulfato de cobre $0,005 \mathrm{~g} / \mathrm{L}$ compõe a solução $\mathrm{E}$ ( $5 \mathrm{~mL}$ 
da solução para $1 \mathrm{~L}$ de meio), sulfato ferro 5,57g/L, EDTA de sódio 7,45g/L compõe a solução $\mathrm{F}$ ( $5 \mathrm{~mL}$ para $1 \mathrm{~L}$ de meio), tiamina $0,1 \mathrm{~g} / \mathrm{L}$, piridoxina $\mathrm{HCl} 0,05 \mathrm{~g} / \mathrm{L}$, ácido nicotínico $0,05 \mathrm{~g} / \mathrm{L}$ compõe a solução $\mathrm{G}(10 \mathrm{~mL}$ para $1 \mathrm{~L}$ de meio), mio-inositol (2g/L) solução $\mathrm{H}(50 \mathrm{~mL}$ para $1 \mathrm{~L}$ de meio), glicina $0,08 \mathrm{~g} / \mathrm{L}$ solução I $(25 \mathrm{~mL}$ da solução pra $1 \mathrm{~L}$ de meio), no meio também é acrescentado sacarose 30g/L e Agar $7 \mathrm{~g} / \mathrm{L}$. Além do acréscimo de variadas concentrações de Cálcio.

\section{Preparação do meio MS/2:}

Foram utilizados 1L de água destilada, tendo a homogeneização com sacarose e ágar através do auxílio do agitador magnético e posteriormente sendo acrescentado os nutrientes citados anteriormente. Após o ajuste de $\mathrm{pH}$ para 5,7, o meio foi aquecido em forno de micro-ondas para a fervura e distribuído igualmente em frascos de vidro, tampado com papel laminado e papel filme respectivamente. Para esterilizado na autoclave com o tempo de 30 minutos.

Desinfestação das sementes:

Por um minuto, as sementes sofreram imersão em etanol a $70 \%$, e depois por 15 minutos no hipoclorito $2 \%$ e por fim, foram lavadas em água destilada.

Inoculação das sementes:

Inicialmente houve a esterilização dos frascos utilizando etanol a $70 \%$. O processo de inoculação foi realizado na cabine de fluxo continuo sendo as pinças utilizadas para o procedimento, flambadas a cada semente inoculada. Depois da inoculação, os frascos foram vedados com papel filme e levados para a sala de crescimento, com condições de temperatura e luminosidade propicia para o desenvolvimento do nabo, para a coleta após 15 dias, 30 dias e 45 dias e armazenado sob refrigeração.

\section{Extração da enzima e análise da atividade peroxidásica:}

Para a obtenção do extrato bruto, primeiramente o tubérculo coletado foi lavado, separado e pesados em porções de $0,1000 \mathrm{~g}$, macerada no almofariz junto a $10 \mathrm{~mL}$ de tampão fosfato $(0,05 \mathrm{~mol} / \mathrm{L})$, com $\mathrm{pH} 6,5$ e filtrado.

A atividade enzimática da peroxidase de rabanete (RAP) foi determinada por método colorimétrico, baseado na mudança de absorvância a $470 \mathrm{~nm}$ devido à formação do produto de oxidação do guaiacol, o tetraguaiacol. HIRATA et al., (1998).

\section{RESULTADOS E/OU DISCUSSÃO}

Na figura 1 se apresentam os experimentos de germinação realizados no horto florestal.

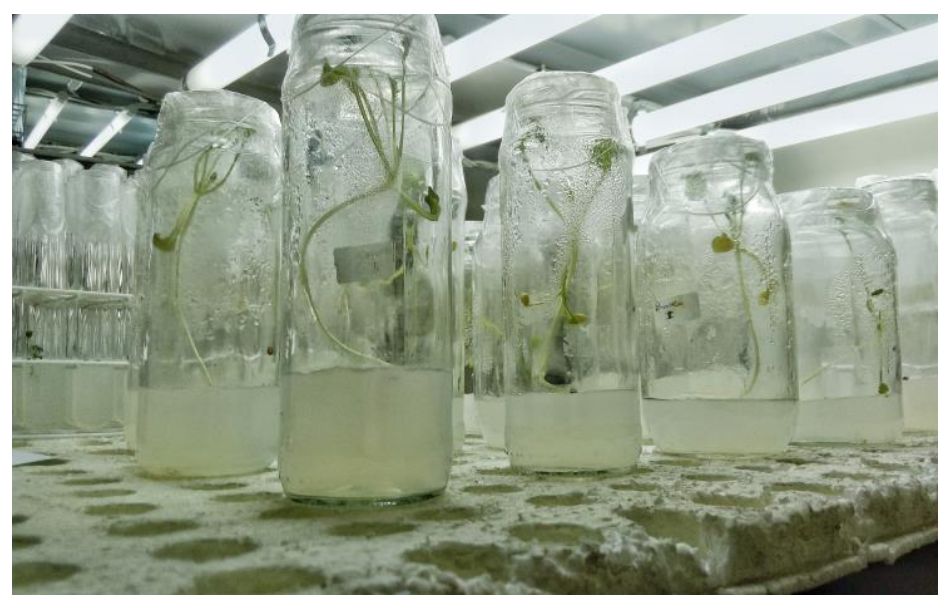

Figura 1. Germinação das sementes do nabo

As sementes do nabo Raphanussativus var. acanthioformis começaram a germinar no quinto dia no meio de cultura Muraschige e Skoog (MS) 
As sementes de nabo cultivadas em meio MS, com apenas influência de sais e vitaminas essenciais para o crescimento do nabo, apresentou uma atividade peroxidasica considerável na amostra colhida no décimo quinto dia com atividade de $0,38 \mathrm{U} / \mathrm{mg} \mathrm{em}$ comparação aos demais dias. As amostras colhidas no trigésimo dia apresentaram o menor grau de atividade da enzima peroxidase de $0,15 \mathrm{U} / \mathrm{mg}$.

$\mathrm{Na}$ figura 1, se apresentam os resultados obtidos da atividade enzimática da peroxidase no processo de germinação das sementes do nabo em diferentes tempos de coleta utilizando o meio de cultura MS.

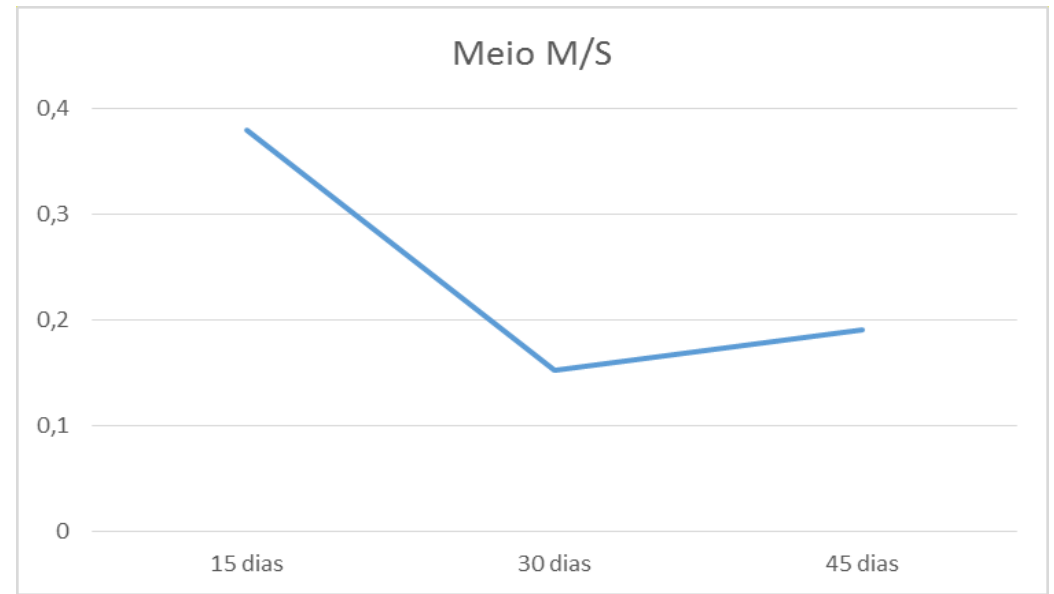

Figura 2: Atividade de enzima peroxidase em diferentes dias em meio MS.

Na figura 2 podemos observar que a maior atividade enzimática foi obtida no início da germinação, aos quinze dias.

As sementes cultivadas em meio MS adicionando solução de cloreto de cálcio $\left(\mathrm{Ca}^{2+}\right)$ com concentração de $10 \mu \mathrm{M}$, figura 3, também apresentaram maior atividade de $0,30 \mathrm{U} / \mathrm{mg}$ no decimo quinto dia, e menor atividade de $0,26 \mathrm{U} / \mathrm{mg}$ no quadragésimo quinto dia comprovando que para melhor obtenção da enzima peroxidase é após 15 dias da sua germinação.

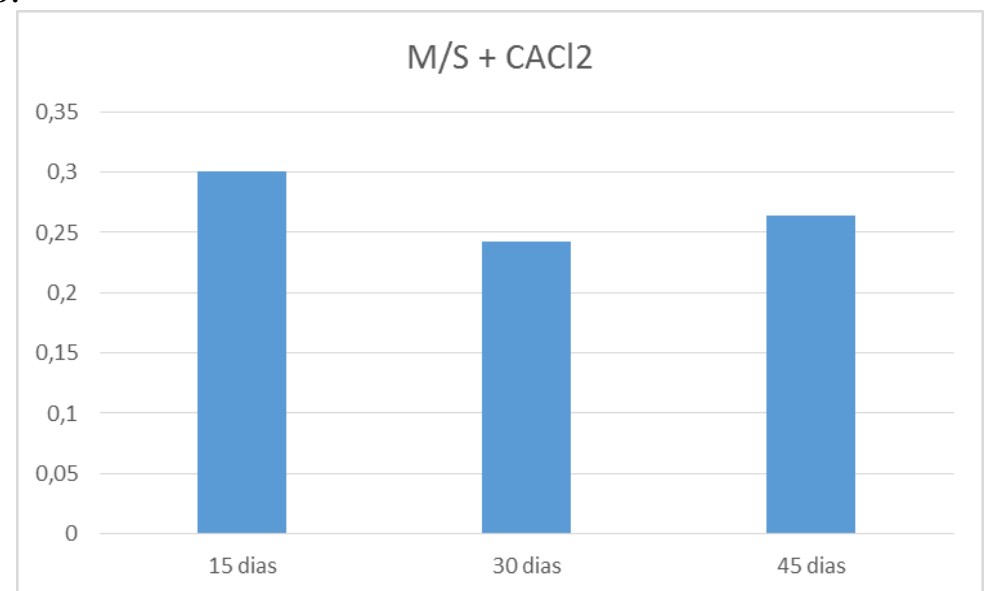

Figura 3: Atividade da enzima peroxidase em diferentes dias de germinação em meio MS sob influência de solução de cloreto de cálcio, $10 \mu \mathrm{M}$.

Ao comparar a atividade da enzima peroxidasica no processo de germinação no meio MS em relação ao meio MS com acréscimo de solução de cloreto de cálcio de concentração $10 \mu \mathrm{M}$, figura 3 , podemos observar que somente tem influência do íon $\mathrm{Ca} 2+$ a partir do trigésimo dia. A utilização do cloreto de cálcio no meio de crescimento MS provocou uma redução da atividade enzimática das sementes de nabo, sendo perceptível que sua adição ao meio não é favorável. 


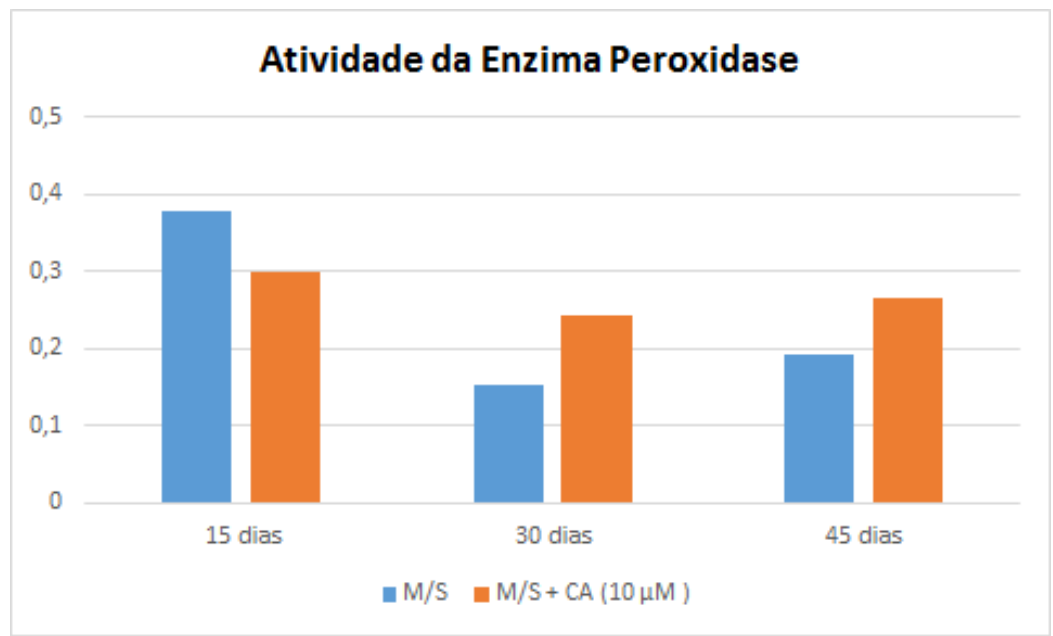

Figura 4: Comparação atividade de enzima peroxidase em diferentes dias em meio M/S sob influência de Cálcio $10 \mu \mathrm{M}$.

\section{CONSIDERAÇÕES FINAIS}

Segundo os experimentos realizados, o melhor dia de colheita da semente germinada é no decimo quinto dia.

O acréscimo de íons cálcio na concentração de $10 \mu \mathrm{M}$ ao meio de cultura não aumenta a atividade enzimática.

\section{REFERÊNCIAS}

HIRATA, T. et al..1998 E poxidation ofstyrenes with the peroxidase from the culture cells of Nicotianatabacum, Tetrahedron, 54, p. 1599316003.

OLIVEIRA, A. S. 2009. Características agronômicas e qualidade de sementes de nabo forrageiro em função da densidade de semeadura e do espaçamento. Minas Gerais, 5p.

ZERAIK, A. E. et al.. 2008. Desenvolvimento de um spot test para o monitoramento da atividade da peroxidase em um procedimento de purificação. vol 31, n 4, Quim. Nova.

FELIBERTO-FILHO, O. et al. 2002. Uso analítico de tecidos e de extratos brutos vegetais como fonte enzimática. vol 25, n. 3, Quimica Nova. 